\title{
Physical activity in patients with COPD
}

\author{
H. Watz*, B. Waschki*, T. Meyer ${ }^{\#}$ and H. Magnussen*
}

ABSTRACT: The present study aimed to measure physical activity in patients with chronic obstructive pulmonary disease (COPD) to: 1 ) identify the disease stage at which physical activity becomes limited; 2) investigate the relationship of clinical characteristics with physical activity; 3) evaluate the predictive power of clinical characteristics identifying very inactive patients; and 4) analyse the reliability of physical activity measurements.

In total, 163 patients with COPD (Global Initiative for Chronic Obstructive Lung Disease (GOLD) stage I-IV; BODE (body mass index, airway obstruction, dyspnoea, exercise capacity) index score 0-10) and 29 patients with chronic bronchitis (normal spirometry; former GOLD stage 0) wore activity monitors that recorded steps per day, minutes of at least moderate activity, and physical activity levels for 5 days ( 3 weekdays plus Saturday and Sunday).

Compared with patients with chronic bronchitis, steps per day, minutes of at least moderate activity and physical activity levels were reduced from GOLD stage II/BODE score 1, GOLD stage III/BODE score 3/4 and from GOLD stage III/BODE score 1, respectively. Reliability of physical activity measurements improved with the number of measured days and with higher GOLD stages. Moderate relationships were observed between clinical characteristics and physical activity. GOLD stages III and IV best predicted very inactive patients.

Physical activity is reduced in patients with chronic obstructive pulmonary disease from Global Initiative for Chronic Obstructive Lung Disease stage II/ body mass index, airway obstruction, dyspnoea, exercise capacity score 1. Clinical characteristics of patients with chronic obstructive pulmonary disease only incompletely reflect their physical activity.

KEYWORDS: 6-minute walking distance, activities of daily living, chronic obstructive pulmonary disease, clinical chronic obstructive pulmonary disease

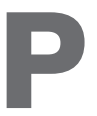

hysical activity is an important clinical parameter related to morbidity and mortality in many chronic diseases [1]. In chronic obstructive pulmonary disease (COPD) the level of physical activity reported by patients is related to lung function decline [2], hospitalisations [3] and mortality [4].

Physical activity is defined as any bodily movement produced by skeletal muscles that results in energy expenditure beyond resting energy expenditure [1]. Physical activity can be quantified with self-report questionnaires [5-7], motion sensors, such as pedometers or accelerometers [5, 7], and with methods assessing free-living energy expenditure, such as the doubly labeled water technique [6]. Self-reported physical activity is often subject to recall bias [7], correlates only poorly with objectively quantified physical activity in patients with COPD [8,9], and does not provide an accurate estimate of free-living energy expenditure [6]. Pedometers and accelerometers generate objective data in terms of quantifying steps or body movements performed over a period of time [5]. However, estimating total daily energy expenditure from body movement counts has been shown to be inaccurate $[10,11]$. Recently, a multisensor armband (SenseWear Pro armband; BodyMedia, Inc., Pittsburgh, PA, USA) became available. It incorporates a biaxial accelerometer that records steps per day, and physiological indicators of energy expenditure. In patients with COPD, the SenseWear Pro armband provides a valid and reproducible estimate of energy expenditure during walking at a slow to moderate pace in a laboratory setting [12], and a high correlation between steps per day and movement counts as measured by a different accelerometer [13].

Physical activity in terms of body movements, walking time and standing time has been shown to be reduced in patients with severe COPD [14, 15]. However, it is currently unknown at which

\section{AFFILIATIONS}

*Pulmonary Research Institute Hospital Grosshansdorf, Center for Pneumology and Thoracic Surgery, Grosshansdorf, and

\#Institute of Social Medicine,

Medical University Lübeck, Lübeck, Germany.

CORRESPONDENCE

H. Watz

Pulmonary Research Institute

Hospital Grosshansdorf

Center for Pneumology and Thoracic Surgery

Woehrendamm 80

Grosshansdorf

Germany

Fax: 494102601245

E-mail: h.watz@pulmoresearch.de

Received:

February 162008

Accepted after revision:

September 292008

SUPPORT STATEMENT

This study was supported by an unrestricted research grant from Astra Zeneca and by the Dr Fritz Meyer Struckmann Foundation. The funding sources had no role in the study design, collection, analysis, or interpretation of the data or in the decision to submit the paper for publication.

STATEMENT OF INTEREST

A statement of interest for this study can be found at www.erj.ersjournals. com/misc/statements.shtml 
clinical stage of the disease limitations of physical activity are first displayed. Furthermore, the relationships between physical activity and clinical characteristics reflecting the disease severity, such as the degree of airway obstruction, distance walked in $6 \mathrm{~min}$, self-reported grade of dyspnoea and clinical stages of COPD, need to be investigated as, to date, data are inconclusive or have never been evaluated. For example, some studies have found substantial correlations between airway obstruction and physical activity $[8,14]$, while others found no $[16,17]$ or only loose [15] relationships. Previous studies indicate that the 6-min walking distance (6MWD) might best reflect physical activity [8, 15], while a recent study found airway obstruction to correlate with physical activity better than 6MWD [18].

Habitual physical activity is known to be highly variable [19, 20]. Therefore, reliability of physical activity measurements needs to be investigated further in patients with COPD as it is currently unknown how many days of physical activity measurement are needed to reliably measure physical activity in patients with COPD.

The present study aimed to: 1) measure physical activity in a substantial number of patients with COPD; 2) investigate the relationships between clinical characteristics and physical activity; 3 ) assess the predictive power of clinical characteristics identifying very inactive patients; and 4) analyse the reliability of physical activity measurements. A group of patients with normal lung function and symptoms of chronic bronchitis, who were matched for social and lifestyle-associated confounders of physical activity, served as a control.

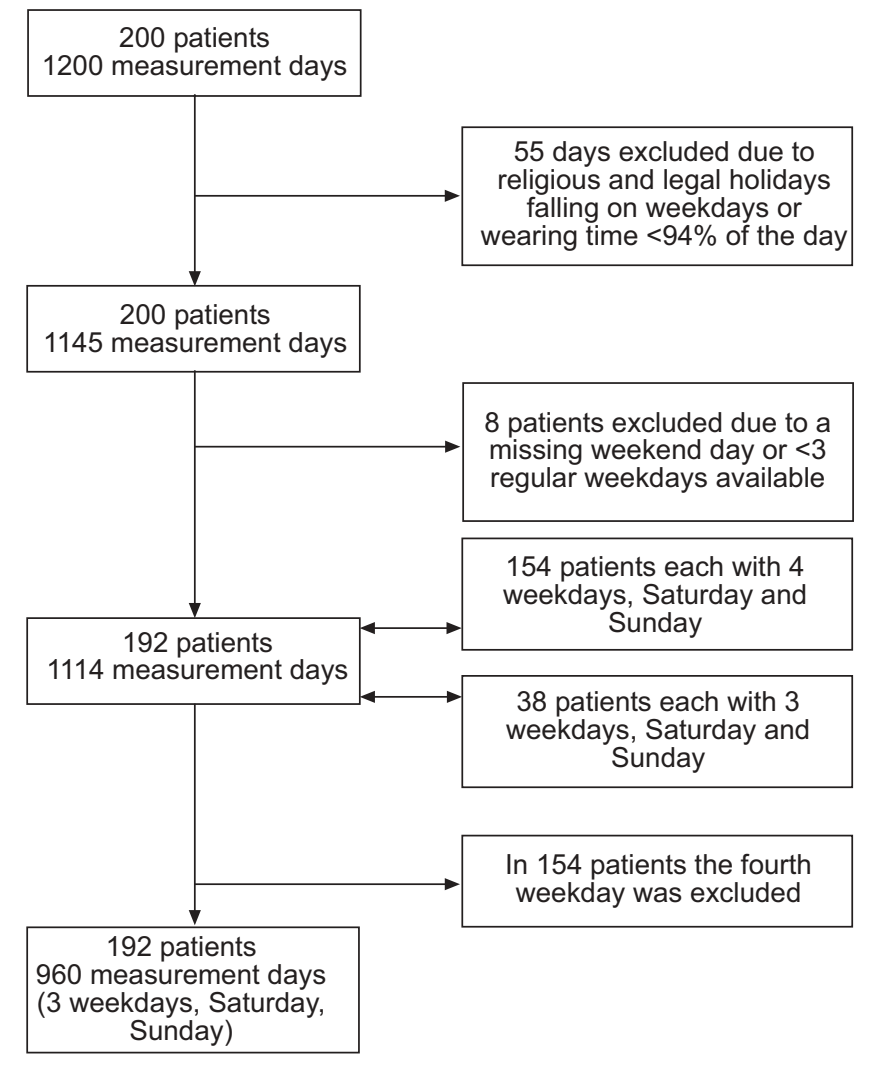

FIGURE 1. Numbers of patients and measurement days.

\section{METHODS}

\section{Study population}

In total, 170 patients with COPD (128 males, 42 females) and 30 patients with chronic bronchitis ( 23 males, seven females) were recruited between February 2006 and November 2006 at the Pulmonary Research Institute at Hospital Grosshansdorf (Grosshansdorf, Germany). Details of the COPD population at the institute have been published previously [13]. Patients with COPD had to be free of an exacerbation for at least 2 months. Post-bronchodilator spirometry was performed using established reference values [21]. Patients with chronic bronchitis served as a control group matched for social and lifestyleassociated confounders of physical activity, such as smoking habits, alcohol consumption and educational status [22, 23]. The patients fulfilled the criteria of being "at risk" (stage 0) for COPD according to the former staging system of the Global Initiative for Chronic Obstructive Lung Disease (GOLD), i.e. chronic cough and sputum production but normal spirometry [24]. The study was approved by the local ethics committee of SchleswigHolstein (Germany), and participants gave their written informed consent. Eight patients (seven with COPD and one with chronic bronchitis) were excluded from analysis (fig. 1).

\section{Physical activity}

\section{Clinical characteristics of COPD patients}

All patients with COPD were classified according to the current GOLD criteria [25] and the criteria of the BODE (body mass index, airway obstruction, dyspnoea, exercise capacity) index [26].

Dyspnoea was assessed by the modified Medical Research Council (MMRC) dyspnoea scale, which is part of the BODE index [26]. Furthermore, the Medical Research Council (MRC) dyspnoea scale (same descriptors as MMRC) has been shown to be a simple method categorising patients with COPD in terms of their disability [27]. Levels of dyspnoea are graded as follows. Grade 0: "I only get breathless with strenuous exercise"; grade 1: "I get short of breath when hurrying on the level or up a slight hill"; grade 2: "I walk slower than people of the same age on the level because of breathlessness or have to stop for breath when walking at my own pace on the level"; grade 3: "I stop for breath after walking 100 yards or after a few minutes on the level"; grade 4: "I am too breathless to leave the house".

The 6-min walk test was conducted according to current guidelines on a 30-m corridor [28]. The 6-min walk test measures the global and integrated responses of all organ systems involved during exercise [28], has been shown to be an important parameter related to morbidity and mortality in COPD [29, 30], and is also part of the BODE index [26].

Receiver operating characteristic curves were used to analyse the sensitivity, specificity and accuracy of the clinical characteristics (GOLD stages, BODE score, 6MWD, airway obstruction (forced expiratory volume in one second; FEV1) and MMRC) in serving as predictors of very inactive patients with COPD. The positive and negative predictive values and likelihood ratios were also calculated.

Parameters and measurement

Parameters of physical activity were as follows: steps per day; minutes of at least moderate activity (defined as any physical 
activity $>3$ metabolic equivalents); and physical activity level. Physical activity was measured using a multisensor armband (SenseWear Pro armband), which is worn on the upper right arm over the triceps muscle. The armband was described previously in a validation study for patients with COPD [12]. Briefly, it incorporates a biaxial accelerometer that records steps per day and physiological sensors of energy expenditure. The physical activity level was calculated by dividing the total daily energy expenditure by whole-night sleeping energy expenditure [13]. A physical activity level $\geqslant 1.70$ defines an active person [6], 1.40-1.69 defines a predominantly sedentary person [6], and $<1.40$ defines a very inactive person [31]. A person with a physical activity level of 1.2 is usually chair- or bed-bound [31].

\section{Days of analysis}

Patients wore the SenseWear armband for 8 days. To obtain the armband patients visited the Pulmonary Research Institute on the first day and returned on the final day to return the device. The first and last days were not used for analysis because of an incomplete measurement of the day and a bias due to the fact that the patients had to visit the Pulmonary Research Institute. Therefore, data from 6 days (4 weekdays plus Saturday and Sunday) of measurement were available for most patients.

Patients were told to wear the armband $24 \mathrm{~h} \cdot$ day $^{-1}$ with the exception of the time spent on personal hygiene. Wearing time was recorded by the armband. For a valid day of activity measurement, the threshold was set at $22.5 \mathrm{~h}$ of wearing time (94\% wearing time per day). Days below that threshold were excluded from analysis.

As one aim was to assess the day-to-day variability of physical activity, including the amount of physical activity performed on weekdays versus weekend days, legal and religious holidays falling on a weekday were excluded (fig. 1).

As another aim was to compare the physical activity between patients of different disease stages according to GOLD or BODE the current authors tried to keep the study population as large as possible. In total, eight patients had to be excluded from analysis due to the fact that a weekend day was missing or fewer than three regular weekdays were available. In the remaining 192 patients, 1,114 measurement days were available. Of these patients, 154 patients had a measurement of 4 weekdays, Saturday and Sunday, and 38 patients had a measurement of 3 weekdays, Saturday and Sunday. To maintain a study population of 192 patients the present authors systematically excluded the fourth weekday in 154 patients (fig. 1), grouped the days of measurement into weekday-1, weekday-2, weekday-3, Saturday and Sunday, and analysed 960 days of activity monitoring.

\section{Variability and reliability of measurement}

The variability of physical activity between days was analysed by repeated measures ANOVA. First, it was determined whether mean physical activity per day was different across all measured days. In the case of a significant difference between all measured days, the current authors analysed whether this was caused by a difference between Saturday and weekdays, Sunday and weekdays, or a difference between weekdays themselves.

The reliability of physical activity measurement was assessed by the intra-class correlation coefficient, calculated as follows:

$$
\text { Intra-class coefficient }=\sigma_{\mathrm{b}}{ }^{2} /\left[\sigma_{\mathrm{b}}{ }^{2}+\left(\sigma_{\mathrm{w}}{ }^{2} / k\right)\right]
$$

where $\sigma_{b}{ }^{2}$ is the between-subject variance, $\sigma_{w}{ }^{2}$ is the withinsubject variance and $k$ is the number of measurement days. An intra-class correlation coefficient $\geqslant 0.8$ indicates that the measured physical activity captures at least $80 \%$ of the variation of physical activity of the group and is the generally accepted value for a multiple day intra-class correlation in accelerometer studies [32-34]. The intra-class correlation coefficient was calculated for every possible combination of days. To ensure that no bias resulted from exclusion of the fourth weekday in 154 patients, the mean values of the physical activity parameters assessed on 5 days ( 3 weekdays plus Saturday and Sunday) versus 6 days (4 weekdays plus Saturday and Sunday) were compared.

\section{General statistics}

General statistics included ANOVA for linear trend, least significant difference post hoc analysis, and parametric and nonparametric correlations.

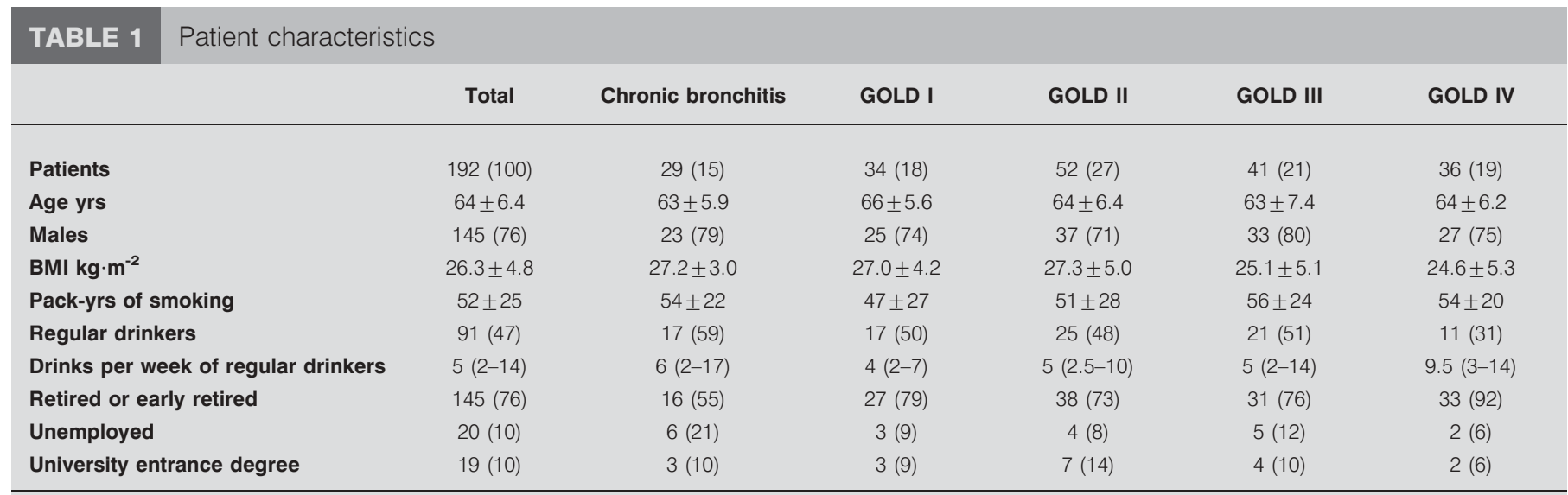

Data are presented as $\mathrm{n}(\%)$, mean \pm SD or median (interquartile range). GOLD: Global Initiative for Chronic Obstructive Lung Disease; BMI: body mass index. 


\section{TABLE 2 Lung function}

\begin{tabular}{|c|c|c|c|c|c|c|}
\hline FEV $1 \%$ pred & $62.8 \pm 26.2^{\#}$ & $99.4 \pm 10.3$ & $90.0 \pm 8.7$ & $63.0 \pm 8.1$ & $40.6 \pm 5.1$ & $32.8 \pm 11.4$ \\
\hline FEV $1 /$ FVC & $51.9 \pm 15.6$ & $74.9 \pm 4.7$ & $62.9 \pm 6.7$ & $52.7 \pm 9.2$ & $39.4 \pm 8.4$ & $36.2 \pm 8.6$ \\
\hline Capillary $\mathrm{PO}_{2}{ }^{\circ} \mathrm{mmHg}$ & $69.9 \pm 8.5$ & $76.2 \pm 9.6$ & $71.0 \pm 6.7$ & $71.2 \pm 7.7$ & $69.7 \pm 6.1$ & $60.4 \pm 5.8$ \\
\hline Capillary $\mathrm{PCO}_{2}{ }^{\top} \mathrm{mmHg}$ & $37.8 \pm 4.8$ & $34.9 \pm 3.8$ & $36.0 \pm 3.8$ & $37.6 \pm 3.9$ & $38.0 \pm 3.3$ & $42.6 \pm 6.1$ \\
\hline
\end{tabular}

Data are presented as mean \pm SD. GOLD: Global Initiative for Chronic Obstructive Lung Disease; FEV1: forced expiratory volume in one second; \% pred: \% predicted; FVC: forced vital capacity; $\mathrm{PO}_{2}$ : partial pressure of oxygen; $\mathrm{PCO}_{2}$ : partial pressure of carbon dioxide. ${ }^{\#}$ : $\mathrm{FEV} 1 \%$ pred for chronic obstructive pulmonary disease patients only was $56.3 \pm 22.6$; $"$ : data are missing for seven patients. $1 \mathrm{mmHg}=0.133 \mathrm{kPa}$.
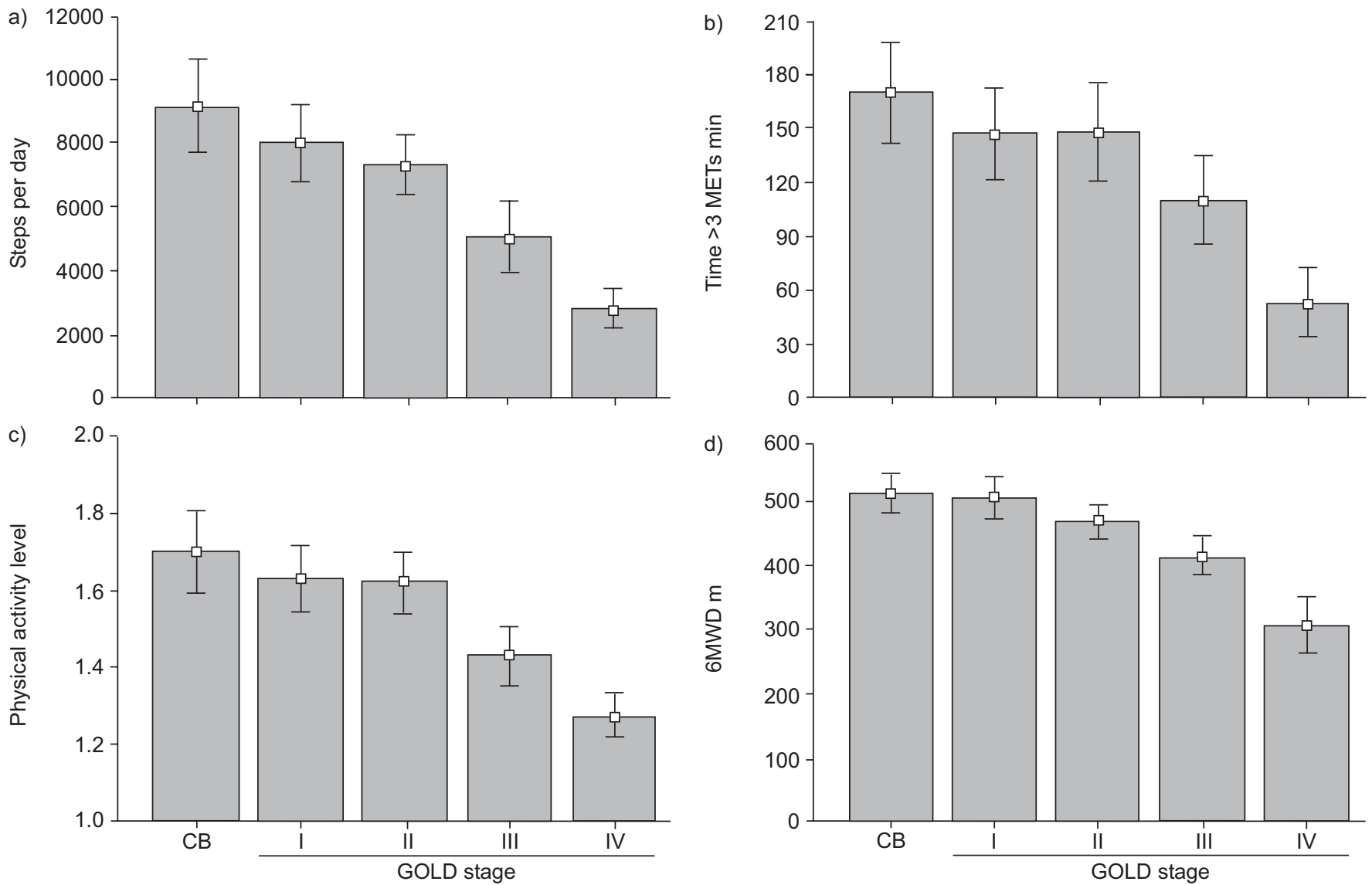

FIGURE 2. a) Steps per day, b) minutes $>3$ metabolic equivalents (METs), c) physical activity level and d) 6-min walk distance (6MWD) for patients with chronic bronchitis (CB) or chronic obstructive pulmonary disease according to Global Initiative for Chronic Obstructive Lung Disease (GOLD) stages. Linear differences from CB to GOLD stage IV were tested by unweighted ANOVA for linear trend. Differences between groups were tested by least significant difference post hoc analysis. a) For linearity, $p<0.001$. GOLD stage II, III and IV were significantly reduced compared with $C B(p=0.02, p<0.001$ and $p<0.001$, respectively). GOLD stage III was significantly reduced compared with GOLD stage I $(p<0.001)$ and II $(p=0.001)$. GOLD stage IV was significantly reduced compared with GOLD stage I, II and III $(p<0.001, p<0.001$ and $p=0.003$, respectively). b) For linearity, $p<0.001$. GOLD stage III and IV were significantly reduced compared with $C B(p=0.002$ and $p<0.001$, respectively). GOLD stage III was significantly reduced compared with GOLD stage I $(p=0.04)$ and II $(p=0.02)$. GOLD stage IV was significantly reduced compared with GOLD stage I, II and III $(p<0.001$, $p<0.001$ and $p=0.002$, respectively). c) For linearity, $p<0.001$. GOLD stage III and IV were significantly reduced compared with CB ( $<<0.001$ ). GOLD stage III was significantly reduced compared with GOLD stage I and II ( $p<0.001)$. GOLD stage IV was significantly reduced compared with GOLD stage I, II and III ( $p<0.001, p<0.001$ and $p=0.006$, respectively). d) For linearity, $p<0.001$. GOLD stage III and IV were significantly reduced compared with $C B(p<0.001)$. GOLD stage III was significantly reduced compared with GOLD stage I $(p<0.001)$ and II $(p=0.009)$. GOLD stage IV was significantly reduced compared with GOLD stage I, II and III ( $<<0.001)$. The bars represent means and vertical lines represent $95 \%$ confidence intervals. 

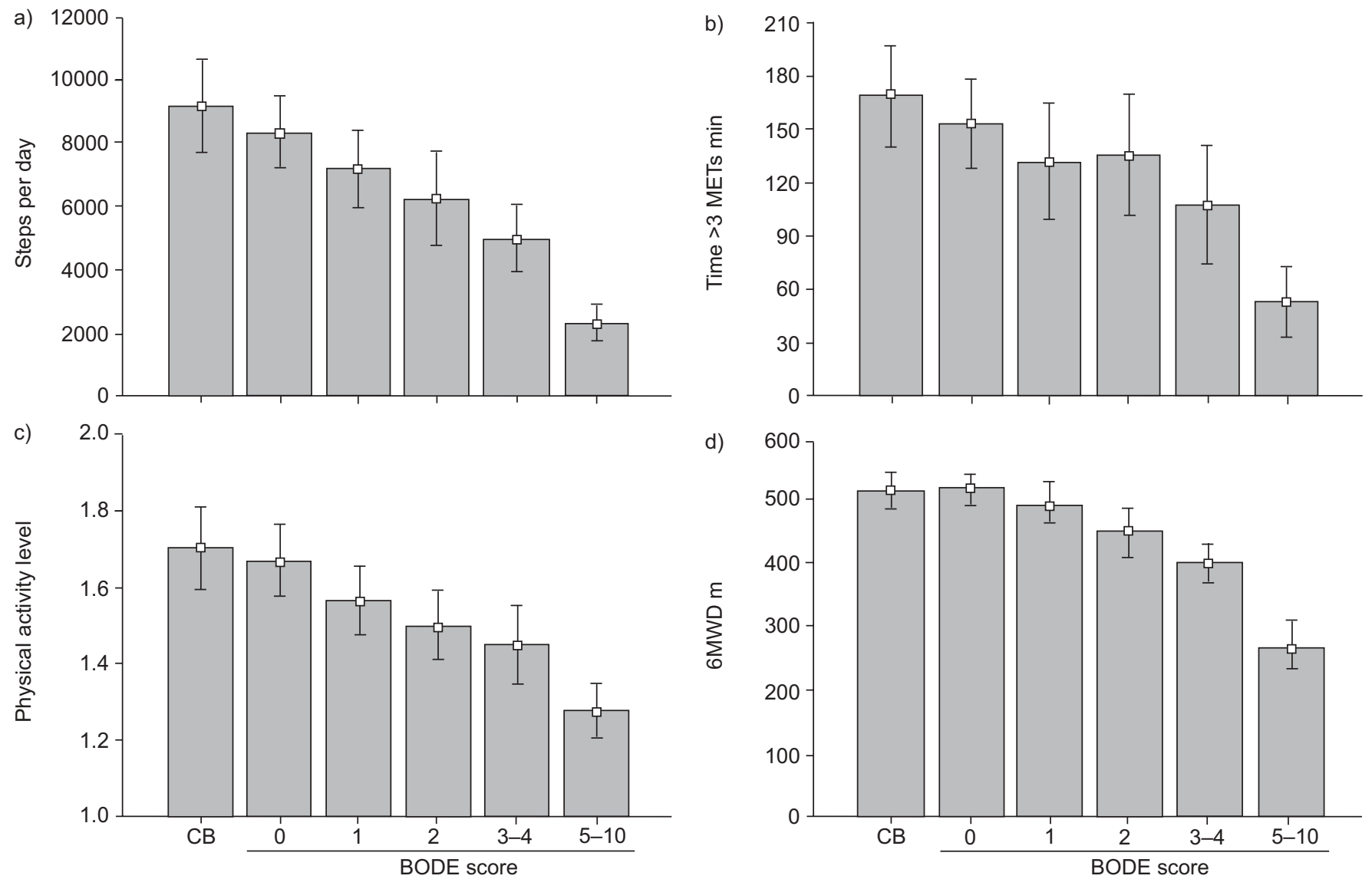

FIGURE 3. a) Steps per day, b) minutes $>3$ metabolic equivalents (METs), c) physical activity level and d) 6-min walk distance (6MWD) for patients with chronic bronchitis (CB) or chronic obstructive pulmonary disease according to BODE (body mass index, airway obstruction, dyspnoea, exercise capacity) quintiles. BODE score 0 : quintile $1(n=39)$; BODE score 1: quintile $2(n=31)$; BODE score 2: quintile $3(n=29)$; BODE score 3-4: quintile $4(n=31)$; BODE score 5-10: quintile 5 ( $n=33)$. Linear differences from $\mathrm{CB}$ to BODE score 5-10 were tested by unweighted ANOVA for linear trend. Differences between groups were tested by least significant difference post hoc analysis. a) For linearity, $p<0.001$. BODE score $1,2,3-4$ and $5-10$ were significantly reduced compared with $C B(p=0.02, p=0.001, p<0.001$ and $p<0.001$, respectively). b) For linearity, $p<0.001$. BODE score $3-4$ and $5-10$ were significantly reduced compared with $C B(p=0.003$ and $p<0.001$, respectively). $c)$ For linearity, $p<0.001$. BODE score $1,2,3-4$ and 5-10 were significantly reduced compared with $C B(p=0.04, p=0.003, p<0.001$ and $p<0.001$, respectively). d) For linearity, $p<0.001$. BODE score 2, 3-4 and 5-10 were significantly reduced compared with $C B(p=0.004, p<0.001$ and $p<0.001$, respectively). The bars represent means and vertical lines represent $95 \%$ confidence intervals.

\section{RESULTS}

Characteristics of the patients are given in tables 1 and 2, and table E1 of the online supplementary material.

Steps per day, minutes of at least moderate activity and physical activity level decreased with the clinical stages according to GOLD or BODE (figs $2 \mathrm{a}-\mathrm{c}$ and $3 \mathrm{a}-\mathrm{c}$ ). Furthermore, physical activity decreased with the grade of dyspnoea (fig. $4 \mathrm{a}-\mathrm{c}$ ). Steps per day, minutes of at least moderate activity and physical activity level decreased from patients with chronic bronchitis to patients in GOLD stage IV by 69,69 and $61 \%$, respectively (fig. $2 a-c$ ). Compared to patients with chronic bronchitis, the proportion of sedentary COPD patients increased markedly in GOLD stage I, BODE score 0 and in COPD patients reporting getting breathless with strenuous exercise only (MMRC 0; fig. 5a-c). The proportion of very inactive patients markedly increased in GOLD stages III and IV, in patients with BODE score 2 or higher, and in patients quoting dyspnoea of MMRC grade 2 or higher (fig. 5a-c). Compared to patients with chronic bronchitis, steps per day, minutes of at least moderate activity and physical activity level were significantly reduced in COPD patients from GOLD stage II/BODE score 1, from GOLD stage III/ BODE score $3 / 4$ (quintile 4) and from GOLD stage III/BODE score 1 , respectively (figs $2 \mathrm{a}-\mathrm{c}$ and $3 \mathrm{a}-\mathrm{c}$ ). Patients reporting MMRC grade 1 dyspnoea or higher had a reduced physical activity (fig. $4 \mathrm{a}-\mathrm{c}$ ).

The 6MWD was significantly reduced in COPD patients from GOLD stage III, from BODE score 2 and from MMRC grade 1 when compared to the $6 \mathrm{MWD}$ of patients with chronic bronchitis (figs $2 \mathrm{~d}, 3 \mathrm{~d}$ and $4 \mathrm{~d}$ ). The $6 \mathrm{MWD}$ decreased from patients with chronic bronchitis to patients in GOLD stage IV by $40 \%$ (fig. 2 d).

Steps per day and the physical activity level were reduced on Sundays in patients with chronic bronchitis and in COPD patients with GOLD stage I-III. Minutes of at least moderate activity were reduced on Sundays in patients with chronic bronchitis and in COPD patients with GOLD stage I and 

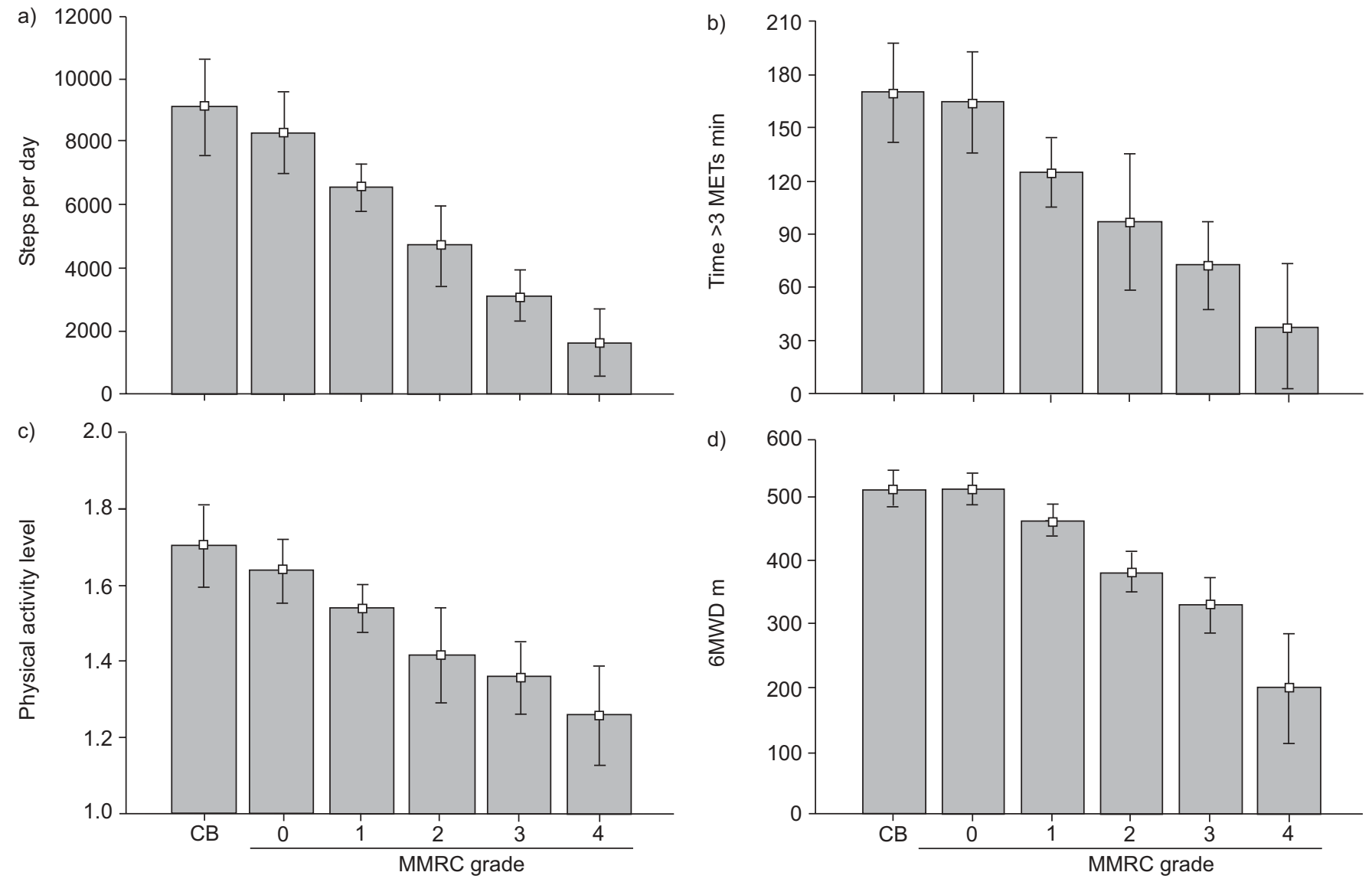

FIGURE 4. a) Steps per day, b) minutes $>3$ metabolic equivalents (METs), c) physical activity level and d) 6-min walk distance (6MWD) for patients with chronic bronchitis (CB) or chronic obstructive pulmonary disease according to the modified Medical Research Council (MMRC) dyspnoea scale. The frequencies of MMRC grade 0 , 1, 2, 3, and 4 were 44, 55, 27, 28 and nine subjects, respectively. Linear differences from CB to MMRC grade 4 were tested by unweighted ANOVA for linear trend. Differences between groups were tested by least significant difference post hoc analysis. a) For linearity, $p<0.001$. MMRC grade 1, 2, 3 and 4 were significantly reduced compared with $C B(p<0.001)$. b) For linearity, $p<0.001$. MMRC grade $1,2,3$ and 4 were significantly reduced compared with $C B(p=0.01, p<0.001, p<0.001$ and $p<0.001$, respectively). $c)$ For linearity, $p<0.001$. MMRC grade 1, 2, 3 and 4 were significantly reduced compared with $C B(p=0.008, p<0.001, p<0.001$ and $p<0.001$, respectively). d) For linearity, $p<0.001$. MMRC grade $1,2,3$ and 4 were significantly reduced compared with $C B(p=0.02, p<0.001, p<0.001$ and $p<0.001$, respectively). Bars represent means and vertical lines represent $95 \%$ confidence intervals.

GOLD stage III (tables E2A-E2C online supplementary data). Depending on the physical activity parameter, any 2-3 days was sufficient for a reliable measurement of physical activity in patients with GOLD stage IV, whereas up to 5 days of measurement were required in patients with GOLD stage I (fig. 6a-c).

The mean values for steps per day, minutes of moderate activity and the physical activity level were virtually unchanged when assessed by 5 or 6 days of measurement $(r \geqslant 0.993, p<0.001$; fig. E1a-c online supplementary material).

Moderate correlations were observed between clinical characteristics of patients with COPD and physical activity (table 3). When using the individual best day of every patient (defined as the highest number for steps per day, minutes of at least moderate activity and the physical activity level) instead of the mean value, correlations between clinical characteristics and parameters of physical activity were basically unchanged (table E3 online supplementary material). The moderate correlations of 6MWD with parameters of physical activity did not significantly change when patients with chronic bronchitis were included in the analysis (fig. E2a-c online supplementary material). In patients with COPD, the GOLD staging system (GOLD stages III and IV) was the best predictor of very inactive patients (fig. 7 and table 4). According to the area under curve, the predictive values and the likelihood ratios, the GOLD staging system was superior to the BODE score, FEV1, 6MWD and MMRC in predicting very inactive patients (table 4).

\section{DISCUSSION}

The main findings of the present study are that significant limitations of physical activity are present in patients with COPD from GOLD stage II/BODE score 1, and that clinical characteristics commonly used to assess COPD severity do not completely reflect physical activity when a broad range of disease severity is evaluated.

Physical activity, measured by a pedometer or an accelerometer, has been previously shown to be reduced in patients with severe COPD compared to healthy subjects [14, 15]. 

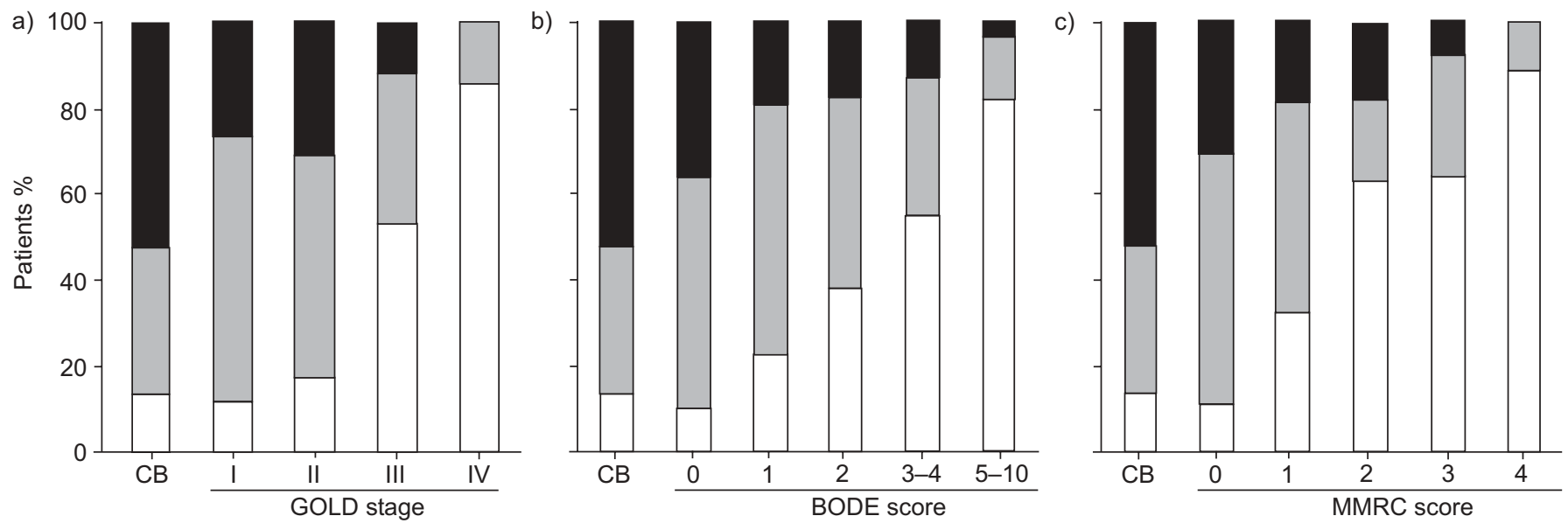

FIGURE 5. Percentage of patients who were active (physical activity level $>1.70$; $\mathbf{m}$ ), predominantly sedentary (physical activity level 1.40-1.69; $\square$ ) or very inactive (physical activity level $<1.40$; $\square$ ) according to a) Global Initiative for Chronic Obstructive Lung Disease (GOLD) stages, b) BODE (body mass index, airway obstruction dyspnoea, exercise capacity) score and c) the modified Medical Research Council (MMRC) dyspnoea scale. CB: chronic bronchitis.

SCHÖNHOFER et al. [14] reported that the daily movement counts were $43 \%$ lower in 25 patients with severe COPD (mean FEV1 $47 \%$ predicted) than in 25 normal healthy subjects. PITTA et al. [15] reported that walking time was $46 \%$ lower and standing time was $35 \%$ lower in 50 patients with severe COPD (mean FEV1 $43 \%$ pred) than in healthy subjects, whereas sitting time was $22 \%$ greater and lying-down time was $200 \%$ greater.
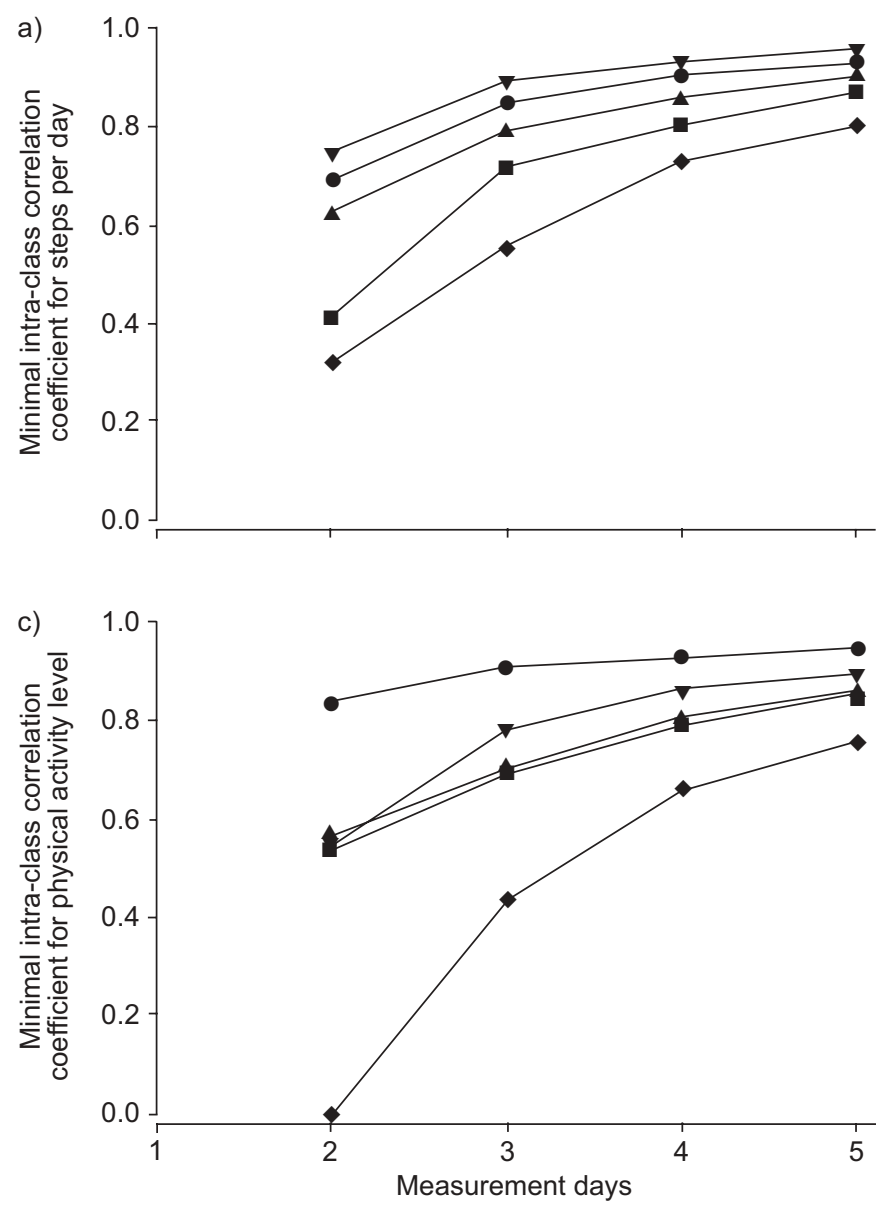

However, when comparing COPD patients with subjects without lung function limitations it was unclear at which clinical stage the reduction of physical activity occurs. In the present study, comparing patients with normal lung function but symptoms of chronic bronchitis with COPD patients, the current authors found that steps per day and physical activity level were significantly reduced from GOLD stage II/BODE

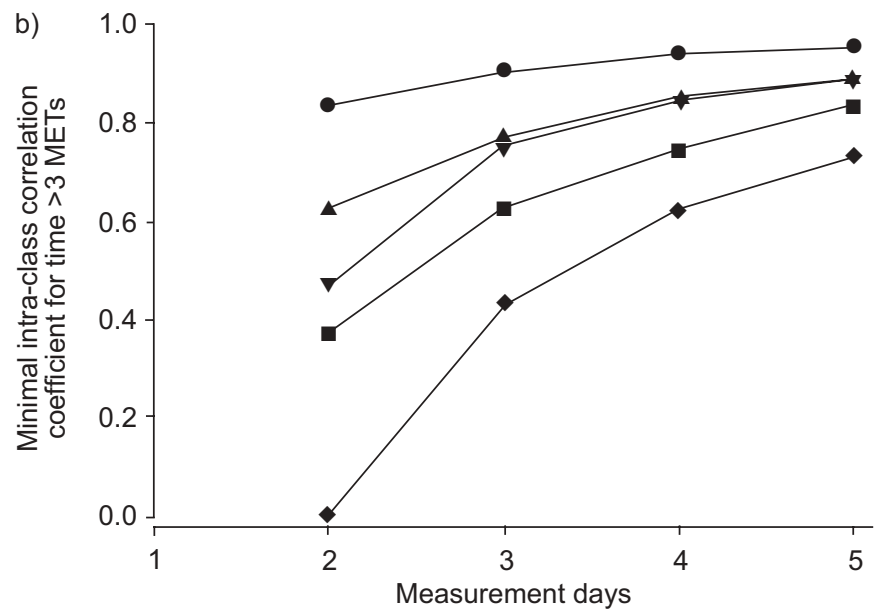

FIGURE 6. Minimal intra-class correlation coefficient for consistency of a) steps per day, b) minutes $>3$ metabolic equivalents (METs) and c) physical activity level across the measured days. Intra-class correlation coefficients were calculated for every possible combination of days: 10 combinations for 2 days; 10 combinations for 3 days; five combinations for 4 days; and one combination for 5 days. : chronic bronchitis; $\mathbf{a}$ : Global Initiative for Chronic Obstructive Lung Disease (GOLD) stage I; $\boldsymbol{\Lambda}$ GOLD stage II; $\mathbf{\nabla}$ : GOLD stage III; $\bullet$ : GOLD stage IV. 
TABLE 3 Correlation coefficients between clinical characteristics and mean physical activity in 163 patients with chronic obstructive pulmonary disease

Steps per day

\section{$-0.58$}

0.63

6MWD

FEV $1 \%$ pred

MMRC grade

BODE score
Time of at least moderate

activity mins
Physical activity level

$\begin{array}{rr}-0.46 & -0.52 \\ 0.47 & 0.46 \\ 0.31 & 0.42 \\ -0.46 & -0.44 \\ -0.44 & -0.49\end{array}$

GOLD: Global Initiative for Chronic Obstructive Lung Disease; 6MWD: 6-min walk distance; FEV1: forced expiratory volume in one second; \% pred: \% predicted; MMRC: modified Medical Research Council dyspnoea scale; BODE: body mass index, airway obstruction, dyspnoea, exercise capacity. Correlations are indicated by Pearson correlations coefficients (FEV1 and 6MWD) and Spearman rank coefficients (GOLD stages, MMRC and BODE score). For every correlation $\mathrm{p}<0.001$.

score 1 and from GOLD stage III/BODE score 1, respectively. This indicates that limitations of physical activity are visible first in patients with GOLD stage II/BODE score 1, but the limitations do not affect the physical activity level at that stage. The present authors speculate that one possible explanation of this discrepancy might be the increased metabolic and ventilatory demands for activities of daily living in patients with COPD compared to healthy subjects [35]. Another possibility might be that patients with COPD in GOLD stage II avoid walking-related activities first, while other activities are not affected at that stage. However, these speculations are clearly subject to further research.

In the present study, there was a physical activity level of 1.7 in patients with a normal lung function but symptoms of chronic bronchitis (mean age 63 yrs, 79\% males, 55\% retired). In a pooled analysis of physical activity levels of retired and elderly subjects, physical activity levels ranged from 1.58 (27 females only, mean age $68 \mathrm{yrs}$ ) to 1.68 (20 males only, mean age $69 \mathrm{yrs}$ ) [31]. In a recent study investigating the impact of physical

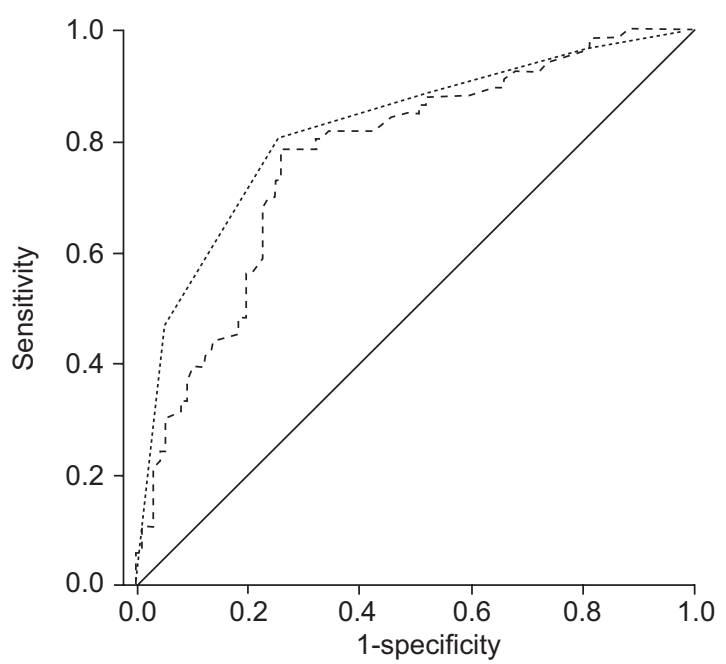

FIGURE 7. Receiver operating characteristic curves for Global Initiative for Chronic Obstructive Lung Disease stages (.......) and 6-min walk test (- . - -) serving as predictors of very inactive patients with chronic obstructive pulmonary disease (physical activity level $<1.40$ ). activity on mortality in 302 healthy older adults (mean age 75 yrs, 50\% males) the mean physical activity level was 1.7 [6]. These data indicate that the patients with chronic bronchitis in the present cohort were within the range of physical activity levels commonly found in that age group.

Another issue that has not been studied in detail is the difference in physical activity between the different clinical stages of COPD. The current study patients in GOLD stage I and GOLD stage II had similar physical activity levels, whereas patients in GOLD stages III and IV differed markedly from patients in the earlier stages and from each other. Even though the absolute values for the physical activity levels did not significantly differ in patients in GOLD stage I and GOLD stage II compared to patients with chronic bronchitis, there was a remarkable shift from patients being active to patients being predominantly sedentary. This shift also occurred in COPD patients reported to suffer from dyspnoea on exertion only or in COPD patients scored as BODE 0.

A health recommendation was published by the Centers for Disease Control and Prevention and the American College of Sports Medicine [36] stating that every adult should perform $30 \mathrm{~min}$ of moderate-intensity physical activity on most, preferably all, days of the week. In fact, this recommendation means that 30 min of moderate physical activity (for example brisk walking) should be accumulated in bouts of at least $10 \mathrm{~min}$ in addition to what sedentary persons normally perform [36]. The present authors were unable to analyse their data with respect to this health guideline as no specific types of activity can be identified by the SenseWear Pro armband. However, as shown previously, it is unlikely that patients with moderate-to-severe COPD are able to accumulate $30 \mathrm{~min}$ of brisk walking as they only walk slowly for $44 \mathrm{~min}$ per day [15].

Variability of physical activity, which is closely linked to reliability of the measurement, is an important issue in accelerometer studies. In the present study, Sunday was a day of reduced physical activity in nearly all patients except those in GOLD stage IV. Former studies in healthy volunteers also found Sunday to be a day of reduced physical activity [33, $34,37]$. The present authors demonstrate that the reliability of accelerometer findings depends on disease severity and on the number of days used for analysis. Assuming the worst consistency across days, it was found that up to 5 days of 


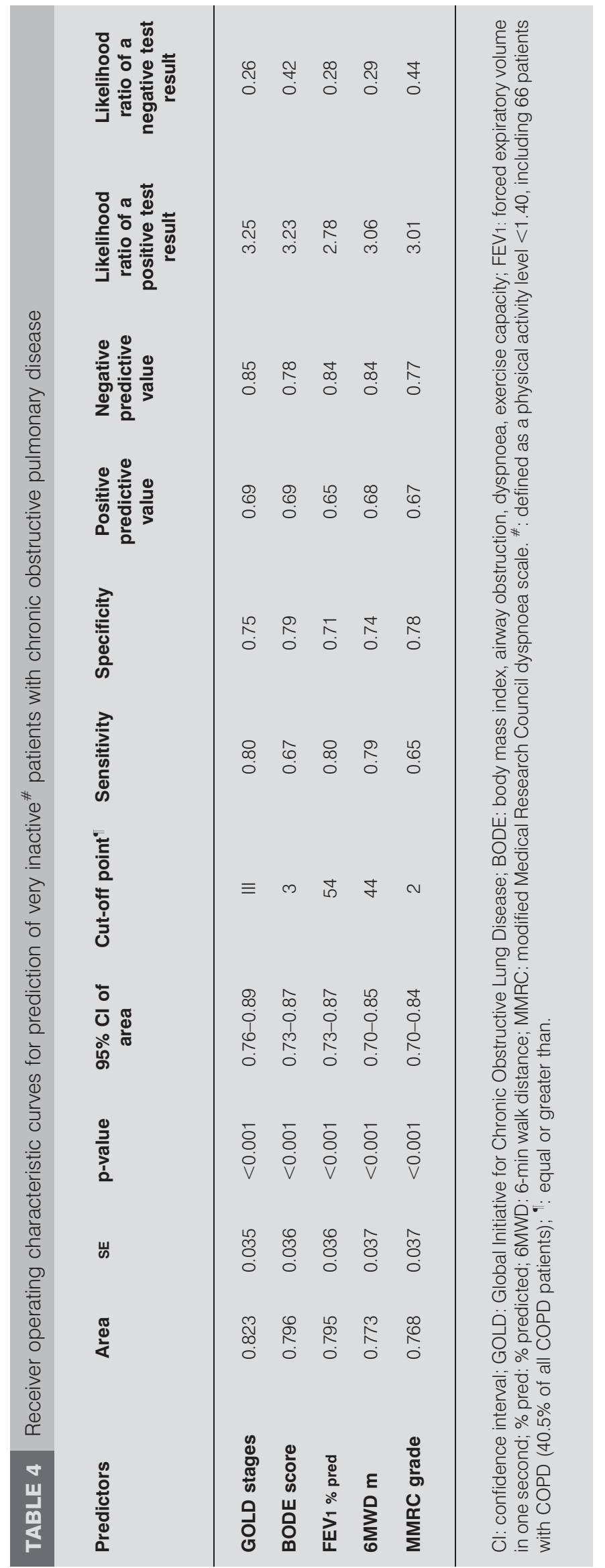

measurement were required to reliably measure physical activity in patients with COPD in GOLD stage I, which indicates that variability of physical activity is higher in less severe COPD. Two other accelerometer studies have previously cited the intra-class correlation coefficient for accelerometer measurement over a period of time in patients with COPD. STEELE et al. [8] had an intra-class correlation coefficient of 0.69 for statistical agreement of 3 days (Friday, Saturday and Sunday) in patients with severe COPD. PITTA et al. [15] showed that 2 days of measurement (weekdays only) were sufficient to obtain an intra-class correlation coefficient of $\geqslant 0.7$. Recently, the number of days needed to reliably measure physical activity in healthy persons was the subject of a review article by TROST et al. [20], who recommended that 3-5 days of accelerometer monitoring were needed to obtain a reliable measure of physical activity. The present data for patients with chronic bronchitis and patients with COPD are in line with this recommendation.

To the current authors' knowledge, the MMRC dyspnoea scale has never been evaluated as a measure of physical activity in patients with COPD. However, MRC grades 4 and 5 (equivalent to MMRC grade 3 and 4) have been shown to categorise patients with COPD in terms of their disability [27]. In the present study, patients with COPD, who were reported to be too breathless to leave the house (MMRC 4), had a physical activity level of 1.26 , which is only slightly higher than a chair- or bed-bound patient [31].

For physicians taking care of patients with COPD it would be ideal to reliably estimate physical activity by COPD-related clinical characteristics assessed by lung function, a simple exercise test or a dyspnoea scale. However, physical activity is a complex multidimensional behaviour that is affected not only by physical attributes, but also by psychosocial and environmental factors that are beyond the scope of those tests $[38,39]$. Overall, moderate relationships were found between the clinical characteristics of COPD patients and their physical activity. The 6MWD showed closer associations with physical activity than airway obstruction, as has been reported previously $[8,15,40]$. However, when compared with the other clinical characteristics used in this study, differences were very small. In the present study, the 6MWD was inferior to airway obstruction and the clinical staging systems in the prediction of very inactive patients. One possibility for this observation might be that physical activity decreased to a greater extent than 6MWD. Furthermore, PITTA et al. [15] have previously shown that $6 \mathrm{MWD}$ is only of limited value as a surrogate marker of physical activity in patients with COPD who walk $>400 \mathrm{~m}$. The mean 6MWD of all the current study patients was $439 \mathrm{~m}$. The mean 6MWD in GOLD stage III was still $414 \mathrm{~m}$, which indicates that most of the current study patients walked $>400 \mathrm{~m}$. In line with the findings of PITTA et al. [15], it can be concluded that the 6MWD is unlikely to replace an objective measurement of physical activity when the whole range of disease severity is investigated.

In the current study, GOLD stages III and IV were shown to be the best predictors of very inactive patients. However, only half of the patients in GOLD stage III were very inactive. Therefore, even with the best predictor, some level of uncertainty remains when identifying very inactive patients. 
There are several study limitations that need to be addressed. First, the present study was a single-centre study performed in patients who were interested in this research project. This may limit applicability across different centres and different clinical settings. Secondly, a control group of never-smokers was not included. Thirdly, the current authors did not perform an analysis of physical activity by season and the winter season is not represented in the recruitment period. However, this should not interfere with the conclusions of the study.

In summary, the present study shows that physical activity is reduced in patients with chronic obstructive pulmonary disease from Global Initiative for Chronic Obstructive Lung Disease stage II/ body mass index, airway obstruction, dyspnoea, exercise capacity score 1, and that clinical characteristics reflecting chronic obstructive pulmonary disease severity do not completely reflect physical activity in patients with chronic obstructive pulmonary disease.

\section{ACKNOWLEDGEMENTS}

The authors would like to thank M. McKenney and O. Holz for the critical review of the manuscript.

\section{REFERENCES}

1 Thompson PD, Buchner D, Pina IL, et al. Exercise and physical activity in the prevention and treatment of atherosclerotic cardiovascular disease: a statement from the Council on Clinical Cardiology (Subcommittee on Exercise, Rehabilitation, and Prevention) and the Council on Nutrition, Physical Activity, and Metabolism (Subcommittee on Physical Activity). Circulation 2003; 107: 3109-3116.

2 Garcia-Aymerich J, Lange P, Benet M, Schnohr P, Anto JM. Regular physical activity modifies smoking-related lung function decline and reduces risk of chronic obstructive pulmonary disease: a population-based cohort study. Am J Respir Crit Care Med 2007; 175: 458-463.

3 Garcia-Aymerich J, Farrero E, Felez MA, Izquierdo J, Marrades RM, Anto JM. Risk factors of readmission to hospital for a COPD exacerbation: a prospective study. Thorax 2003; 58: 100-105.

4 Garcia-Aymerich J, Lange P, Benet M, Schnohr P, Anto JM. Regular physical activity reduces hospital admission and mortality in chronic obstructive pulmonary disease: a population based cohort study. Thorax 2006; 61: 772-778.

5 Pitta F, Troosters T, Probst VS, Spruit MA, Decramer M, Gosselink R. Quantifying physical activity in daily life with questionnaires and motion sensors in COPD. Eur Respir J 2006; 27: 1040-1055.

6 Manini TM, Everhart JE, Patel KV, et al. Daily activity energy expenditure and mortality among older adults. JAMA 2006; 296: 171-179.

7 Ward DS, Evenson KR, Vaughn A, Rodgers AB, Troiano RP. Accelerometer use in physical activity: best practices and research recommendations. Med Sci Sports Exerc 2005; 37: Suppl. 11, S582-S588.

8 Steele BG, Holt L, Belza B, Ferris S, Lakshminaryan S, Buchner DM. Quantitating physical activity in COPD using a triaxial accelerometer. Chest 2000; 117: 1359-1367.
9 Pitta F, Troosters T, Spruit MA, Decramer M, Gosselink R. Activity monitoring for assessment of physical activities in daily life in patients with chronic obstructive pulmonary disease. Arch Phys Med Rehabil 2005; 86: 1979-1985.

10 Leenders NY, Sherman WM, Nagaraja HN, Kien CL. Evaluation of methods to assess physical activity in freeliving conditions. Med Sci Sports Exerc 2001; 33: 1233-1240.

11 Leenders NY, Sherman WM, Nagaraja HN. Energy expenditure estimated by accelerometry and doubly labeled water: do they agree? Med Sci Sports Exerc 2006; 38: 2165-2172.

12 Patel SA, Benzo RP, Slivka WA, Sciurba FC. Activity monitoring and energy expenditure in COPD patients: a validation study. COPD 2007; 4: 107-112.

13 Watz H, Waschki B, Boehme C, Claussen M, Meyer T, Magnussen H. Extrapulmonary effects of chronic obstructive pulmonary disease on physical activity: a cross-sectional study. Am J Respir Crit Care Med 2008; 177: 743-751.

14 Schönhofer B, Ardes P, Geibel M, Köhler D, Jones PW. Evaluation of a movement detector to measure daily activity in patients with chronic lung disease. Eur Respir J 1997; 10: 2814-2819.

15 Pitta F, Troosters T, Spruit MA, Probst VS, Decramer M, Gosselink R. Characteristics of physical activities in daily life in chronic obstructive pulmonary disease. Am J Respir Crit Care Med 2005; 171: 972-977.

16 Garcia-Aymerich J, Felez MA, Escarrabill J, et al. Physical activity and its determinants in severe chronic obstructive pulmonary disease. Med Sci Sports Exerc 2004; 36: 1667-1673.

17 Singh S, Morgan MD. Activity monitors can detect brisk walking in patients with chronic obstructive pulmonary disease. J Cardiopulm Rehabil 2001; 21: 143-148.

18 Walker PP, Burnett A, Flavahan PW, Calverley PM. Lower limb activity and its determinants in chronic obstructive pulmonary disease. Thorax 2008; 8: 683-689.

19 Tudor-Locke C, Ham SA, Macera CA, et al. Descriptive epidemiology of pedometer-determined physical activity. Med Sci Sports Exerc 2004; 36: 1567-1573.

20 Trost SG, McIver KL, Pate RR. Conducting accelerometerbased activity assessments in field-based research. Med Sci Sports Exerc 2005; 37: Suppl. 11, S531-S543.

21 Quanjer PH, Tammeling GJ, Cotes JE, Pedersen OF, Peslin R, Yernault JC. Lung volumes and forced ventilatory flows. Report Working Party Standardization of Lung Function Tests, European Community for Steel and Coal. Official Statement of the European Respiratory Society. Eur Respir J 1993; 6: Suppl. 16, 5-40.

22 Blair SN, Jacobs DR Jr, Powell KE. Relationships between exercise or physical activity and other health behaviors. Public Health Rep 1985; 100: 172-180.

23 Folsom AR, Cook TC, Sprafka JM, Burke GL, Norsted SW, Jacobs DR Jr. Differences in leisure-time physical activity levels between blacks and whites in population-based samples: the Minnesota Heart Survey. J Behav Med 1991; 14: $1-9$.

24 Pauwels RA, Buist AS, Calverley PM, Jenkins CR, Hurd SS. GOLD Scientific Committee. Global strategy for the diagnosis, management, and prevention of chronic obstructive pulmonary disease. NHLBI/WHO Global Initiative for Chronic Obstructive Lung Disease (GOLD) Workshop summary. Am J Respir Crit Care Med 2001; 163: 1256-1276. 
25 Rabe KF, Hurd S, Anzueto A, et al. Global strategy for the diagnosis, management, and prevention of chronic obstructive pulmonary disease: GOLD executive summary. Am J Respir Crit Care Med 2007; 176: 532-555.

26 Celli BR, Cote CG, Marin JM, et al. The body-mass index, airflow obstruction, dyspnea, and exercise capacity index in chronic obstructive pulmonary disease. $N$ Engl J Med 2004; 350: 1005-1012.

27 Bestall JC, Paul EA, Garrod R, Garnham R, Jones PW, Wedzicha JA. Usefulness of the Medical Research Council (MRC) dyspnoea scale as a measure of disability in patients with chronic obstructive pulmonary disease. Thorax 1999; 54: 581-586.

28 ATS Committee on Proficiency Standards for Clinical Pulmonary Function Laboratories. ATS statement: guidelines for the six-minute walk test. Am J Respir Crit Care Med 2002; 166: 111-117.

29 Casanova C, Cote CG, Marin JM, et al. The 6-min walking distance: long-term follow up in patients with COPD. Eur Respir J 2007; 29: 535-540.

30 Cote CG, Casanova C, Marin JM, et al. Validation and comparison of reference equations for the 6-min walk distance test. Eur Respir J 2008; 31: 571-578.

31 Black AE, Coward WA, Cole TJ, Prentice AM. Human energy expenditure in affluent societies: an analysis of 574 doubly-labelled water measurements. Eur J Clin Nutr 1996; 50: 72-92.

32 Baranowski T, de Moor C. How many days was that? Intra-individual variability and physical activity assessment. Res Q Exerc Sport 2000; 71: Suppl. 2, S74-S78.
33 Matthews CE, Ainsworth BE, Thompson RW, Bassett DR Jr. Sources of variance in daily physical activity levels as measured by an accelerometer. Med Sci Sports Exerc 2002; 34: 1376-1381.

34 Tudor-Locke C, Burkett L, Reis JP, Ainsworth BE, Macera CA, Wilson DK. How many days of pedometer monitoring predict weekly physical activity in adults? Prev Med 2005; 40: 293-298.

35 Velloso M, Stella SG, Cendon S, Silva AC, Jardim JR. Metabolic and ventilatory parameters of four activities of daily living accomplished with arms in COPD patients. Chest 2003; 123: 1047-1053.

36 Pate RR, Pratt M, Blair SN, et al. Physical activity and public health. A recommendation from the Centers for Disease Control and Prevention and the American College of Sports Medicine. JAMA 1995; 273: 402-407.

37 Gretebeck RJ, Montoye HJ. Variability of some objective measures of physical activity. Med Sci Sports Exerc 1992; 24: 1167-1172.

38 Caspersen CJ, Powell KE, Christenson GM. Physical activity, exercise, and physical fitness: definitions and distinctions for health-related research. Public Health Rep 1985; 100: 126-131.

39 van Sluijs EM, Griffin SJ, van Poppel MN. A cross-sectional study of awareness of physical activity: associations with personal, behavioral and psychosocial factors. Int J Behav Nutr Phys Act 2007; 4: 53.

40 Behnke M, Wewel AR, Kirsten D, Jorres RA, Magnussen H. Exercise training raises daily activity stronger than predicted from exercise capacity in patients with COPD. Respir Med 2005; 99: 711-717. 